\title{
Utilization of Web-based Information Services among University Students in Malaysian Academic Libraries: A Proposed Conceptual Framework
}

\author{
Husain Hashim*, Shamila Mohamed Shuhidan and Norizan Anwar \\ Universiti Teknologi MARA, Shah Alam, Selangor, Malaysia \\ husainha@uitm.edu.my; shamila@uitm.edu.my; norizan8027@uitm.edu.my \\ *Correspondence: husainha@uitm.edu.my
}

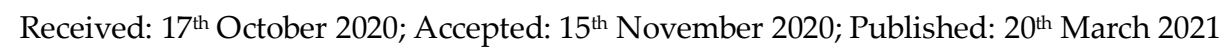

\begin{abstract}
Digital, information, and networked technologies have largely affected the academic libraries and their users in support of 21st education. This development places demands on them to endure seriously the assessment challenges in the aspect of users' utilization of Web-based Information Services, not merely to rely on the implicit value of usage statistics, but also to look into the explicit difference that the specific usage of web-based information services has on users' experience in the form of their perceived scholarly outcomes. In establishing this paper, scoping approach was used as the methodology for preliminary assessment in exploring and analyzing the published research articles from local and international sources. Based on the literature review, this paper aims to propose a conceptual research framework for Malaysian academic libraries comprising three independent variables, namely, library technology, academic library roles, and library learning environment. Besides, information literacy skill is introduced to gain understanding, to what extent, it has a moderating relationship between the independent variables and the university students' utilization of WBIS, the predicted dependent variable that constitutes implicit and explicit values. This framework will be measured by conducting a research involving six public universities in the Klang Valley of Malaysia. In the long run, it is expected to propose a research method and instruments to support the academic libraries in collecting and analyzing data about utilization of web-based information services among university students.
\end{abstract}

Keywords: Web-based information services; Academic library; Library technology; Academic library roles; Information literacy skills; Utilization

\section{Introduction}

The dynamism of technological evolution continues to steer the world of today, and thus can be seen affecting the information needs, wants and behaviors of library users in universities. This trend is revolutionizing the roles of libraries at large, through the adoption of the Internet and mobile devices by taking advantage of the World Wide Web (WWW) and social media sites. Consequently, the digital environment enables library users in having more flexibility in utilizing the web-based information services (WBIS) with many options and better controls over the resources that are available and accessible online.

Given such background, in the effort to optimize the utilization of WBIS, it is inappropriate for the librarians to only focus on implementing advanced technologies at the expense of neglecting the relationship with their users. Past research showed that the supporting role of librarians is still central

Husain Hashim, Shamila Mohamed Shuhidan and Norizan Anwar, "Utilization of Web-based Information Services among University Students in Malaysian Academic Libraries: A Proposed Conceptual Framework", Annals of Emerging Technologies in Computing (AETiC) Print ISSN: 2516-0281, Online ISSN: 2516-029X, pp. 79-85, Vol. 5, No. 5, $2^{\text {th }}$ March 2021, Published by International Association of Educators and Researchers (IAER), DOI: 10.33166/AETiC.2021.05.009, Available: http://aetic.theiaer.org/archive/v5/v5n5/p9.html. 
to users. A study involving the students and academic staff of four (4) Malaysian research-intensive universities, revealed that users are reliant on the online instructions provided by their libraries in the attempt to perform information searches despite enjoying the ease of use and convenience of accessing information sources on the web [1]. In fact, it has prompted another crucial task in the hand of university librarians particularly in imparting information literacy skills to enable students utilizing electronic resources effectively in discovering knowledge and improving academic quality [2].

What is more fundamental is to ensure that the actual purpose for the provision of WBIS must be served accordingly [1], in alignment with the users' needs and their decisions and choices in utilizing the services. In the perspective of users' information literacy skills and utilization of WBIS, as most frameworks are commonly linear and presented as a series of logical, sequential, rational and systematic steps, this sort of view of skills deployment is rather questionable. In reality, students who live in the global and inter-connected world rarely follow the prescribed sequence but are more inclined to the non-linear method [3]. Consequently, this would make them have the feelings of inadequacy, loss, and anxiety due to low self-efficacy belief in dealing with complex and non-linear tasks that eventually may lead them not to utilize academic libraries including WBIS.

Therefore, libraries need to emphasize the rapid changes and influence of networked technologies and should endure seriously the assessment challenges in the aspect of users' utilization or usage of WBIS and the attainment of outcomes. Measuring WBIS is indispensable that library assessment should refocus from merely relying on usage statistics that may not explicitly prove the direct value of a library to its institution, and as such, need to also look into the difference that library usage makes to users' experience and scholarly outcomes [4].

\section{Research Background}

The libraries and librarians nowadays are under great demands for demonstrating, documenting and articulating their performance and value. To date, formal investigation endeavors are still emergent and limited in pursuing studies on the contributions of academic libraries toward essential student outcomes. Previous study at the Universiti Malaysia Pahang (UMP) library [5] revealed students' satisfaction that went beyond the acceptable level of the minimum service received, as well as it surpassed the actual expectations they placed upon those services. Whereas the academicians of the Universiti Malaya (UM) were found to rate the service quality of their academic library right over an average point, while the overall satisfaction level was perceived as satisfactory [6]. As both studies concentrated on assessing user satisfaction, the question of whether or not satisfaction serves an outcome measure has been debated in the literature. While there is an opinion suggesting outcome is similar to user satisfaction, another view argues that user satisfaction is not outcome or even output [7]. This is where libraries need to collect sound and substantial evidence that directly connects their activities and library usage among users to demonstrate positive outcomes.

Hence, a conceptual research framework is proposed to focus on the utilization of WBIS from the context of the implicit value and explicit value of library usage that draws attention to service outputs based on the frequency of use, as well the value proposition of usage contributing to the learning and research outcomes of students. Based on the literature, utilization of WBIS is the identified dependent variable, predicted to have relationship with three (3) independent variables consisting of library technology, academic library roles, and library learning environment. Significantly, information literacy is introduced as a moderating factor in order to gain understanding, to what extent, it has a significant relationship with the independent variables in affecting utilization of WBIS [8].

\section{Literature Review}

Literature related to utilization of WBIS were sought, gathered, analyzed and reviewed. Special attention was given to the academic libraries in the higher learning institutions, particularly to focus on students' needs in relation to their learning and research undertakings. 


\subsection{Utilization of WBIS}

The aspect of the utilization of WBIS intends to look upon the explicit and implicit measures of value at individual level perspective, not only by collecting usage data that has its importance to imply the libraries are used (output dimension), but also in order to gain understanding in the overall perspective of utilization of WBIS, it is also to gauge the purposes and outcomes of use [9].

The explicit measure of students' utilization of WBIS will be associated with outcomes or benefits gained from the actual interaction, engagement, intervention and action taken by them upon the information and materials received from the act of utilizing specific WBIS, for example through reading, synthesizing, reviewing, analyzing and using the contents that would inspire new thinking, improve results, resolve technical problems and help in quicker accomplishment of the given tasks [9].

\subsection{Library Technology Factor}

Living through a wealth of information over the WWW, it is not guaranteed that library users will be able to use digital resources to the optimal extent. A recent literature in Malaysia revealed that users' continued intention to use a digital library is associated with their perceived usefulness as well as ease of use of the WBIS such as Web OPAC and electronic resources [10]. However, when the library systems are not considered user-friendly, and also as when the academic libraries are viewed to largely house text-based materials, users might start to find alternatives [11]. Most of graduate students and faculties have the tendency to start to approach the publisher's website, or rather, using google before eventually forced to go to the library's websites [12]. This frequently occurs as they realize the libraries have subscribed the licensed electronic resources, particularly when they are required to enter login id and password to gain access. Students are more comfortable to begin the search process, for instance from Google due to the convenience and ease of use of the search engine. Additionally, accessibility is another reason that may have an influence on users' intention to use online resources.

\subsection{Roles of Academic Library Factor}

At the Sheffield University, students' failure to understand and recognize the functions and expertise of academic librarians has caused the supports provided to be poorly used [13]. Therefore, academic librarians will need to reconsider their new role as well as to create new services, for instance by becoming partners for students' learning [14].

Furthermore, besides the support for learning and teaching, academic libraries need to promote, foster and be partners in research area. This is supported by the research finding involving the Malaysian postgraduate students that a high majority agreed with the importance of the academic libraries' role in supporting them in research [15]. In this respect, the Purdue University offers the research services including user training on data curation, open access, and research data management that should count the faculty perspective over library perspective [16]. However, it was found that the librarians themselves encountered several key barriers in playing the research support role due to confidence issue and lacking of understanding of the needs of researchers, as well as the faculties were perceived as 'self-sufficient' in research, and thus were not offered much help.

\subsection{Library Learning Environment}

The virtual presence of academic libraries is necessary in conjunction with the changing learning and research information landscape that is characterized by online access to digitized and global content. The physical space of a library has been less valid for many research students because of the self-study nature of research and also, most of them own their personal space at the office or home [17].

The presence of academic libraries in universities not to be restrained to a fixed time and place. In the effort to meet different preferences of users, the university libraries in the United Kingdom (UK) are challenged about the need for "agile learning spaces" through the provision of different 
spaces for individual learning and social learning [18], as users' learning needs are rather diverse than common between them. In this regard, it should inevitably include the implementation of digital technologies, for example, the use of blended learning and the virtual learning environment that will help to transform student's learning. The need to assess and collect the inputs of users on library space is essential to keep aligned with the changing learning behaviors that will continue to evolve, and thus the librarians are urged to make necessary adaptations following those changes.

\subsection{Information Literacy Skills Factor}

Another crucial aspect concerning students' ability to utilize WBIS is related to their information literacy skills. Living in the information-based societies, students should be equipped with information skills to support lifelong learning through which their level of confidence will be boosted in becoming more independent and self-regulated learners. Having access to sophisticated technology and electronic devices without properly equipped with information literacy skills does not assure students' ability to utilize WBIS [19]. This indicates that information literacy can play a moderating role between library technology and the utilization of WBIS, which lacking these skills will cause them not knowing how to search, compare and utilize digital resources in libraries [8]. Essentially, in a study held on the rural residents in Taiwan found that information literacy skills as a moderating role in adopting ICT [20].

The postgraduate students of four (4) public universities in Malaysia demanded the academic libraries to provide the necessary support in their pursuance of research [15]. They highlighted the importance of electronic resources and the provision of library training programs that can develop their information skills in bibliographic citations and data analysis software. Meanwhile, more recently, the findings of a study have somehow developed an understanding that despite the electronic resources not being adequately utilized by students, there is still a significant relationship that occurred involving their information literacy skills and usage of electronic resources.

Another study on the needs of the international students in Australia, it was found and pointed out that the development of library space and information literacy programs significantly boosted and enhanced students' transition and learning [21]. Furthermore, the librarians' role in the implementation of information literacy and maker education is underlined [22]. Librarians are pled to become a companion or guide through the provision of the third space or maker space in their libraries in providing flexibility, freedom and numerous opportunities for students to make full use of the maker hardware, software, and apps that are well integrated with information literacy skills to solve real-world problems.

\section{Methodology}

An assessment of the scope of research literature relating to utilization of WBIS was conducted by implementing scoping approach. Literature reviews were held in exploring and analyzing the published research articles initially attained and compiled from Mendeley, Google Scholar and several electronic databases subscribed by the academic library of University Teknologi MARA. The purpose of using this approach is to locate evidences through the reviews and analysis of the literature contents that helps in identifying key concepts, issues, problems, methods, findings and models/frameworks. Some selected keywords and phrases were used in an attempt to retrieve relevant articles such as "web-based information services", "usage/utilization of library services", "measurement and evaluation of information services", "roles of academic libraries/librarians", "information system models", "outcomes and impacts of academic libraries", "digital library", "library learning environment", "library space management", "information literacy skills" and "digital literacy". Presented in table 1 are the identified variables and dimensions, as a result of the analysis and review of the literature to be incorporated in the proposed conceptual framework.

Table 1. Variables and dimensions derived from literature

\begin{tabular}{|c|c|c|}
\hline Variable & Dimension & Literature \\
\hline Library Technology (IV) & Ease of use, ease of access, usefulness & {$[1,10,11,20,23]$} \\
\hline Roles of Academic Library (IV) & Learning support, research support & {$[13,14,15,16]$} \\
\hline
\end{tabular}




\begin{tabular}{|c|c|c|}
\hline Library Learning Environment (IV) & Physical space, virtual space & {$[13,17,18,22]$} \\
\hline Information Literacy Skills (Moderating) & Cognitive, ethical & {$[2,8,15,16,19,20,21]$} \\
\hline Utilization of WBIS (DV) & Output, outcome & {$[4,7,8,9,10]$} \\
\hline
\end{tabular}

\section{Proposed Conceptual Framework}

The proposed framework aims to investigate the utilization of WBIS at the Malaysian academic libraries among university students. There are three (3) independent variables have been initially determined from the literature review process, comprising library technology, roles of libraries and library learning environment that would be perceived by students as having an influence on their utilization of such services. Library technology dimension is concerned with users' perceived ease of use, usefulness, and accessibility factors in influencing their intention to utilize WBIS. Next, the provision of WBIS is linked to the role of academic libraries, particularly focusing on the functions, expertise/knowledge, customer relationship and partnership/collaboration with faculty to support learning and research activities of users. Lastly, the library learning environment serves as the third variable to encompass the interlinked between the physical and virtual presence of academic libraries as a place for library collections and services, learning support and information seeking.

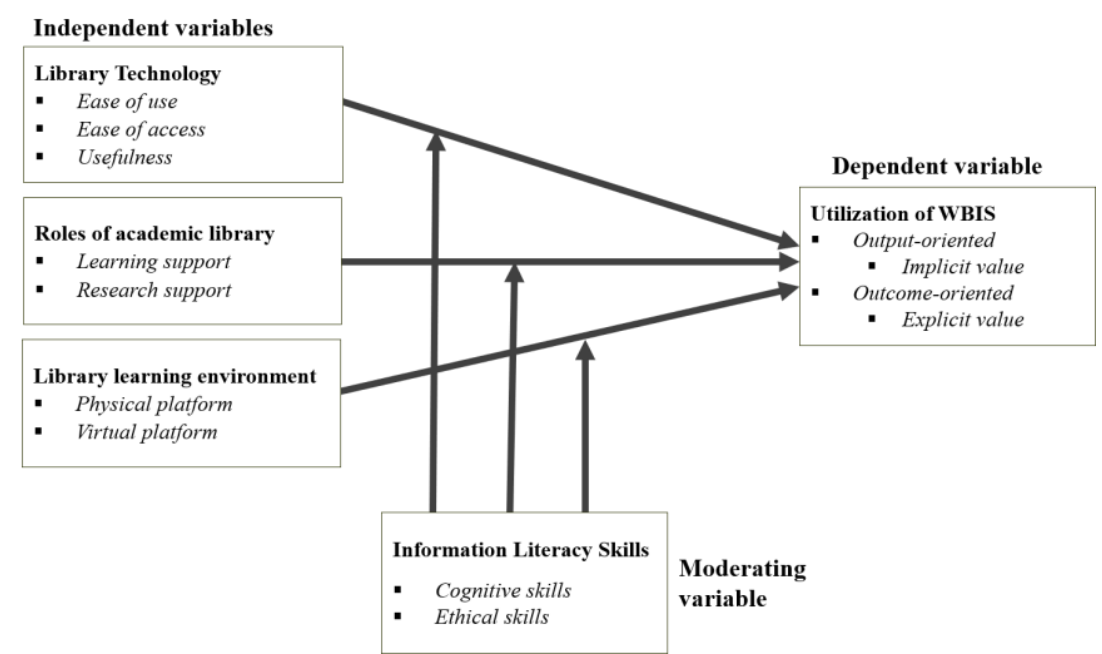

Figure 1. Proposed conceptual research framework

A crucial addition to the framework is information literacy skill that is predicted to have a strong correlation with the use of electronic resources among students. As such, information literacy skills have been identified as a moderating variable that its introduction is expected to strengthen the effects of the three (3) independent variables on students' utilization of WBIS.

As the dependent variable predicted to have a relationship with the above independent and moderating variables, utilization of WBIS will take into account of two facets of library usage that is to gauge library outcome perspective (explicit measure - values explicitly attributed to benefits) as well as library output perspective (implicit measure - values implied from the amount of usage data). The explicit measure of students' utilization of WBIS will be associated with outcomes or benefits gained from the actual interaction, engagement, intervention and action taken by them upon the information and materials received from the act of utilizing specific WBIS, for example through reading, synthesizing, reviewing, analyzing and using the contents that would inspire new thinking, improve results, resolve technical problems and help in quicker accomplishment of the given tasks [9]. The implicit measure of utilization of WBIS will cater for the frequency or amount of use of five (5) selected service points of WBIS, which are provided via Web-based platforms comprising library website, electronic databases (e-journals and e-books), reference consultations (via online chat and email), OPAC (via online access) and library's institutional repository.

\section{Conclusion}

The proposed framework is expected to provide useful and insightful findings in making the academic libraries well-informed in regard with the status of utilization of WBIS among Malaysian 
university students. For this purpose, it constitutes library technology, roles of academic libraries and library learning environment, the three (3) independent variables recognized and predicted to have relationship with students' utilization of WBIS, the dependent variable that comprises the implicit and explicit values in relation to academic and research undertakings. Furthermore, information literacy skill is the moderating variable that is anticipated to have effects on both the dependent and independent variables. All these variables will be measured by conducting a research involving six (6) public universities in the Klang Valley of Malaysia. In the long run, it will offer a research method as well as instruments for collecting and analyzing data about utilization of WBIS to be materialized by the academic librarians of the higher learning institutions in Malaysia.

\section{References}

[1] Kiran, K. and Singh, D. (2012). Modeling Web-based library service quality. Library and Information Science Research. Vol. 34, pp 184-196. Available: https://doi.org/10.1016/j.lisr.2012.02.005.

[2] Abunandi, I. (2018). A technology-dependent information literacy model within the confines of a limited resources environment. Information Technology and Libraries. Vol. 37, No. 4, pp 119-135. Available: https://doi.org/10.6017/ital.v37i4.9750.

[3] Markless, S. (2009). A new conception of information literacy for the digital environment in higher education. Nordic Journal of Information Literacy in Higher Education, 1(1), pp 25-40. Available: https://doi.org/10.15845/noril.v1i1.17.

[4] Salisbury, F. and Peasley, J. (2018). Measuring the academic library: translating today's inputs and outputs into future impact and value. Information and Learning Science. Vol. 119, No. 1/2, pp 109-120. Available: https://doi.org/10.1108/ILS-07-2017-0068.

[5] Suziyana M. D., Mohd Yusof T., Nurhaizan M. Z. and Fadzida I. (2016). Surveying users' perception of academic library services quality: a case study in Universiti Malaysia Pahang (UMP) Library. The Journal of Academic Librarianship. Vol. 42, pp 38-43. Available: https://doi.org/10.1016/j.acalib.2015.10.006.

[6] Kiran, K. (2010). Service quality and customer satisfaction in academic libraries: Perspectives from a Malaysian university. Library Review. Vol. 59, No. 4, pp 261-273. Available: https://doi.org/10.1108/00242531011038578.

[7] Poll, R. and Payne, P. (2006). Impact measures for libraries and information services. Library Hi Tech. Vol. 24, No. 4, pp 547-562. Available: https://doi.org/10.1108/07378830610715419.

[8] Ukachi, N. B. (2015). Information literacy of students as a correlate of their use of electronic resources in university libraries in Nigeria. The Electronic Library. Vol. 33 No. 3, pp 486-501. Available: http://dx.doi.org/10.1108/EL-05-2013-0085.

[9] Tenopir, C., Christian, L. and Kaufman, J. (2019). Seeking, reading, and use of scholarly articles: an international study of perceptions and behavior of researchers. Publications. Vol. 7, No. 18. Available: https://doi.org/10.3390/publications7010018.

[10] Abdul Rahman, A.R. and Mohezar, S. (2020). Ensuring continued use of a digital library: a qualitative approach. The Electronic Library. Available: https://doi-org.ezaccess.library.uitm.edu.my/10.1108/EL-122019-0294.

[11] Matusiak, K. K. (2012). Perceptions of usability and usefulness of digital libraries. Journal of Humanities \& Arts Computing. Vol. 6, No. 1/2, pp 133-147. Available: https://doi.org/10.3366/ijhac.2012.0044.

[12] Matthews, J. (2012). Assessing library contributions to university outcomes: the need for individual student level data. Library Management. Vol. 33, No. 6/7, pp 389-402. Available: https://doi.org/10.1108/01435121211266203.

[13] Bickley, R. and Corrall, S. (2011). Student perceptions of staff in the information commons: a survey at the University of Sheffield. Reference Services Review. Vol. 39, No. 2, pp 223-243. Available: https://doi.org/10.1108/00907321111135466.

[14] Meulemans, Y. and Carr, A. (2013). Not at your service: building genuine faculty-librarian partnerships. Reference Services Review. Vol. 41, No. 1, pp 80-90. Available: https://doi.org/10.1108/00907321311300893

[15] Rasul, A. and Singh, D. (2010). The role of academic libraries in facilitating postgraduate students' research. Malaysian Journal of Library \& Information Science, 15. Vol. No. 3, pp 75-84.

[16] Creaser, C. and Spezi, V. (2014). Improving perceptions of value to teaching and research staff: The next challenge for academic libraries. Journal of Librarianship and Information Science. Vol. 46, No. 3, pp 191206. Available: https://doi.org/10.1177/0961000613477678.

[17] Beard, C. and Bawden, D. (2012). University libraries and the postgraduate student: physical and virtual spaces. New Library World. Vol. 113, No. 9/10, pp 439-447. Available: https://doi.org/10.1108/03074801211273911. 
[18] Beard, J. and Dale, P. (2010). Library design, learning spaces and academic literacy. New Library World. Vol. 111, No. 11/12, pp 480-492. Available: https://doi.org/10.1108/03074801011094859.

[19] Kumar, S., Ochoa, M., and Edwards, M. (2012). Considering information literacy skills and needs: Designing library instruction for the online learner. Communications in Information Literacy. Vol. 6, No. 1, pp 91-106. https://doi.org/10.15760/comminfolit.2012.6.1.120

[20] Yu, Tai-Kuei, Lin, Mei-Lan and Liao, Ying-Kai (2017). Understanding factors influencing information communication technology adoption behavior: the moderators of information literacy and digital skills. Computers in Human Behavior. Vol. 71, pp 196-208. Available: http://dx.doi.org/10.1016/j.chb.2017.02.005

[21] Hughes, H., Hall, N. and Pozzi, M. (2017). Library experience and information literacy learning of first year international students: an Australian case study. Communications in information literacy. Vol. 11, No. 2, pp 302-323.

[22] Mann L. (2019). Making a place for makerspaces in information literacy. Reference \& User Services Quarterly. Vol. 58, No. 2, pp 82-86. Available: http://dx.doi.org/10.5860/rusq.58.2.6927.

[23] Asyraf, A., Hazimi, F. and Norliana, A. M. (2020). Investigating digital library success using the DeLone and McLean Information System Success 2.0: the analysis of common factor based structural equation modeling. Journal of Physics: Conference Series. Vol. 1529, No. 2000. Available: https://doi.org/10.1088/1742$\underline{6596 / 1529 / 4 / 042052 .}$

(C) 2020 by the author(s). Published by Annals of Emerging Technologies in Computing (AETiC), under the terms and conditions of the Creative Commons Attribution (CC BY) license which can be accessed at http://creativecommons.org/licenses/by/4.0. 